\title{
Anisotropic Deformation Model for Hawkesbury Sandstone Incorporating Inherent Mobilised Shear Strength
}

\author{
Noorfaizah Hamzah ${ }^{1}$, Nur Ain Mat Yusof ${ }^{2, *}$, Mohd Jamaludin Md Noor ${ }^{2}$ \\ ${ }^{1}$ School of Civil Engineering, College of Engineering, Universiti Teknologi MARA, 40450 Shah Alam, Selangor, Malaysia \\ ${ }^{2}$ School of Engineering, College of Engineering, Universiti Teknologi MARA (Pahang), 26400 Bandar Tun Abdul Razak Jengka, \\ Pahang, Malaysia
}

Received December 3, 2020; Revised July 26, 2021; Accepted August 9, 2021

\begin{abstract}
Cite This Paper in the following Citation Styles
(a): [1] Noorfaizah Hamzah, Nur Ain Mat Yusof, Mohd Jamaludin Md Noor, "Anisotropic Deformation Model for Hawkesbury Sandstone Incorporating Inherent Mobilised Shear Strength," Civil Engineering and Architecture, Vol. 9, No. 5A, pp. 93 - 100, 2021. DOI: 10.13189/cea.2021.091311.
\end{abstract}

(b): Noorfaizah Hamzah, Nur Ain Mat Yusof, Mohd Jamaludin Md Noor (2021). Anisotropic Deformation Model for Hawkesbury Sandstone Incorporating Inherent Mobilised Shear Strength. Civil Engineering and Architecture, 9(5A), 93 - 100. DOI: 10.13189/cea.2021.091311.

Copyright $\bigcirc 2021$ by authors, all rights reserved. Authors agree that this article remains permanently open access under the terms of the Creative Commons Attribution License 4.0 International License

\begin{abstract}
An extensive study on modelling progressive Hawkesbury Sandstone degradation by anisotropic deformation subjected to monotonic loadings is presented and discussed in this study. Hawkesbury Sandstone was used due to its unique behaviour, which was initially assumed to be a uniform testing lithology with respect to grain size, compressive strength and stiffness. This study identified a theoretical approach to the anisotropic model of rock deformation. The model utilizes the stress-strain curve to derive the development of mobilised shear strength and applies it to the rock to simulate how it compresses in anisotropic. Monotonic loading tests were performed in triaxial conditions at variations of confining pressure, $4 \mathrm{MPa}$ and $8 \mathrm{MPa}$. An increment of confining pressure was used to obtain elevation in the stress-strain curve. Progressive monotonic loading changed the mechanical characteristics of the rock; the level of the applied stress is compressed axially and then expanded laterally. During applied loading, the rock may experience damage or rock failure; the correlation between the magnitude of the mobilised shear strength and the axial stress associated with it is regarded as an intrinsic property in the rock mass. The stress-strain behaviour of rocks under anisotropic stress conditions can be predicted using this method. The mobilised minimum friction angle is used to determine the location of the mobilised shear strength
\end{abstract}

envelope. The results reveal that the mobilised intrinsic shear strength is developed if the rock is forced to compaction. This is evidenced by the envelope rotating upward to the shear force envelopes during failing. Consequently, it can be deduced that the cementation (c') of the rock increases.

Keywords Hawkesbury Sandstone, Mobilised Shear Strength, Monotonic Load, Stress-Strain, Shear Strength Envelope

\section{Introduction}

Rocks can be a challenge as they included different types of inhomogeneities and discontinuities. In recent rock study, more emphasis is placed on rock behaviour that is subject to loading under varying loading conditions, in various stress-strain rates and pattern of behaviour that emerges after rock failure. The study of rock behaviour under different confining pressure is to demonstrate the application of loading condition during construction activity. Due to the fact that the intrinsic attributes of the rock are founded through loading, the rock may fail when it reaches the monotonic failure stress. Such mechanisms 
may erode the stability of geomaterials and excavation boundaries, posing a significant risk of failure. Therefore, prediction of the peak strength is a certain step in order to avoid those hazards from happening. The deformation of evaporating sedimentary rock under cyclic loading needs further studies, which were based on their findings, during monotonic stress, the peak strengths of their rock samples decreased to varying degrees under cyclic loading. [1].

The damage or failure of faulted rock slope is a quite difficult problem in geotechnical engineering, and attention has been drawn from researchers for a long time. Under static loadings such as gravity or engineering building, the rock material within a certain zone behind the tip of a crack/fault will behave strain-softening property due to the action of stress erosion or chemical erosion.

Anisotropy is an essential characteristic that should be paid close attention to in rock engineering, regardless of the application. Mostly due to the presence of cleavage, foliation, bedding planes, schistosity, joints, and micro or macro fractures, the anisotropy of rock properties can be ascribed to anisotropy [2].

In this study, Hawkesbury sandstone was used, which belongs to the catalogue sedimentary rock. The Hawkesbury sandstone is chosen as it was initially assumed to be a uniform testing lithology with respect to grain size, compressive strength, and stiffness. During uniaxial testing, the discrepancy between sample strength was observed due to the heterogeneity of Hawkesbury Sandstone. Therefore, the monotonic test is generally used with a condition, which, by assuming entire samples to be tested, are identical and have used average peak strength which were obtained from the monotonic test as the peak value for every Hawkesbury Sandstone specimen tested. The assessment of the Hawkesbury sandstone in terms of the stress-strain curve for primary loading testing has been studied by Taheri et al. [3].

Based on the previous researcher, the rock condition has been changed by the weathering process. Some unnatural characteristics of rock engineering in comparison with the fresh rock to residual soil are shown [4]. Physically, sandstone rock is considered as soft rock, and sandstone was formed when sand is buried under successive layers of sediment. The following Table 1 compares the physical characteristics of sandstone and shale [5].

Table 1. Comparative of physical properties of weathered sandstone and shale of Kenny hill formation (Mohamed et al., 2007) [5]

\begin{tabular}{|c|c|c|c|c|c|}
\hline Rock samples & $\begin{array}{l}\text { Hardness (hand } \\
\text { sample) }\end{array}$ & Rebound hardness & $\begin{array}{l}\text { Surface texture and } \\
\text { lamination }\end{array}$ & $\begin{array}{c}\text { Dry density } \\
\mathbf{k N} / \mathrm{m}^{3}\end{array}$ & Slake \\
\hline $\begin{array}{c}\text { Slightly } \\
\text { weathered } \\
\text { Sandstone } \\
\text { (BP2g, } \\
\text { BP2s) }\end{array}$ & $\begin{array}{l}\text { Very hard } \\
\text { and intact }\end{array}$ & $>30$ & $\begin{array}{c}\text { Smooth and } \\
\text { intact }\end{array}$ & $\begin{array}{c}2.4- \\
2.6\end{array}$ & 98 \\
\hline $\begin{array}{l}\text { Moderately } \\
\text { weathered } \\
\text { Sandstone } \\
\text { (BP3) BP4 }\end{array}$ & $\begin{array}{c}\text { Hard and } \\
\text { slightly } \\
\text { disintegrate }\end{array}$ & $5-30$ & $\begin{array}{l}\text { Slightly } \\
\text { massive } \\
\text { and gritty }\end{array}$ & $\begin{array}{c}2.2- \\
2.7\end{array}$ & 94 \\
\hline $\begin{array}{c}\text { Highly } \\
\text { weathered } \\
\text { Sandstone } \\
\text { (BP5) }\end{array}$ & $\begin{array}{c}\text { Breakable } \\
\text { and easily } \\
\text { disintegrate }\end{array}$ & $10-15$ & $\begin{array}{l}\text { Partially } \\
\text { massive } \\
\text { and gritty }\end{array}$ & $\begin{array}{c}2.0- \\
2.7\end{array}$ & - \\
\hline $\begin{array}{c}\text { Slightly } \\
\text { weathered } \\
\text { shale (S2) }\end{array}$ & $\begin{array}{c}\text { Easily } \\
\text { broken and } \\
\text { disintegrate }\end{array}$ & dented & $\begin{array}{l}\text { Very gritty } \\
\text { and } \\
\text { massive }\end{array}$ & $\begin{array}{c}1.5- \\
1.9\end{array}$ & 46 \\
\hline $\begin{array}{c}\text { Moderately } \\
\text { to Highly } \\
\text { weathered } \\
\text { shale }\end{array}$ & $\begin{array}{l}\text { Hard and } \\
\text { slake }\end{array}$ & $<20$ & $\begin{array}{l}\text { Soapy and } \\
\text { intact }\end{array}$ & $\begin{array}{c}2.4- \\
2.5\end{array}$ & 92 \\
\hline S5 & $\begin{array}{c}\text { Breakable } \\
\text { and easily } \\
\text { slake }\end{array}$ & $10-20$ & $\begin{array}{c}\text { Powdery } \\
\text { and slightly } \\
\text { massive }\end{array}$ & $\begin{array}{c}2.2- \\
2.4\end{array}$ & 96 \\
\hline S5a & $\begin{array}{l}\text { Breakable } \\
\text { and slake }\end{array}$ & dented & $\begin{array}{l}\text { Powdery, } \\
\text { gritty and } \\
\text { massive }\end{array}$ & $\begin{array}{c}2.5- \\
2.6\end{array}$ & 92 \\
\hline
\end{tabular}


Predicting the rock failure by modelling is important in order to ensure the ability of the foundation or infrastructure to withstand pressure and remain stable. According to Yang et al. [6], when considering multi-peak deformation of rock, the condition and patterns of a rock mass strength are critical. Fragmented rock masses influence the design and construction of civil and mining structures because they have both high strength and low deformability. Furthermore, the significance of obtaining not only the peak strength of rocks but also the complete stress-strain curve of rocks through laboratory testing has been acknowledged, as this could have an impact on the structural stability and strength of the rock [7].

\section{Materials and Methods}

\subsection{Specimen Preparation}

The rock samples of Hawkesbury Sandstone were cored in a circular cylindrical- shape for monotonic compressive testing as in Figure 1. The ISRM (International Society for Rock Mechanics) standards [8] were used to prepare the rock samples, which have an approximate height of $100 \mathrm{~mm}$ and a diameter of $42 \mathrm{~mm}$. The samples of Hawkesbury Sandstone were exhibited in Figure 1(a). A pair of axial and lateral strain gauges was secured, as shown in Figure 1(b). The technique used is as follows and was performed to ensure that the strain gauges remain undamaged, and the strain gauges placed on shields are as follows:

1) To eliminate rough surfaces, gauges were first coated with epoxy (PS XH07F), allowed to dry for 24 hours, and then sanded to acquire a smooth surface
2) Strain gauges should be applied to the surface that is smooth and covered with polyurethane for protection.

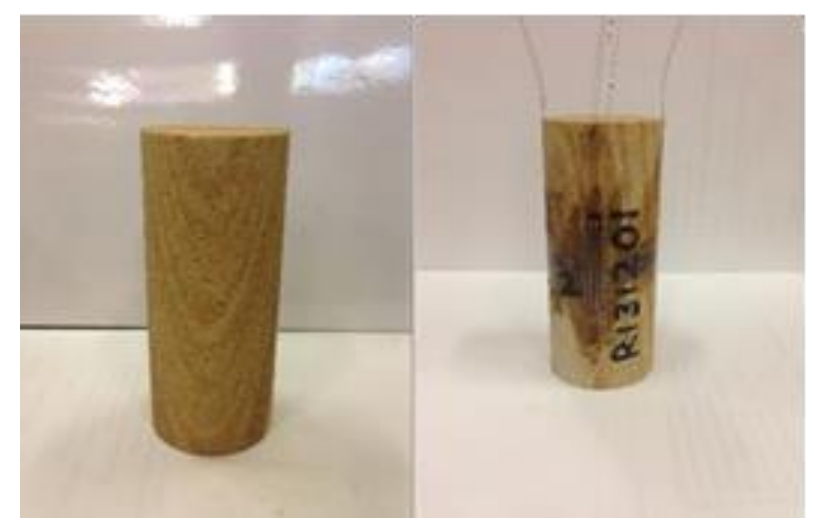

(a)

(b)

Figure 1. The cylindrical core sample used for monotonic compressive testing (a) Hawkesbury Sandstone sample (b) strain gauges applied on specimen

\subsection{Experimental Setup and Procedure}

To perform uniaxial tests, the INSTRON 1342 machine, which is a testing machine with servo control and a loading capacity of $250 \mathrm{kN}$ and capable of performing the loading rate from 0.001 to $20 \mathrm{~mm} / \mathrm{s}$. Two linear variable differential transformers (LVDT) are installed in the machine, which are machine LVDT and external LVDT. Throughout the testing, the machine has been mounted with LVDT to determine the direction of the displacement (up or down) and the amount of displacement during the testing. Figure 2 demonstrates the experimental configuration for the uniaxial compression test used in this study.

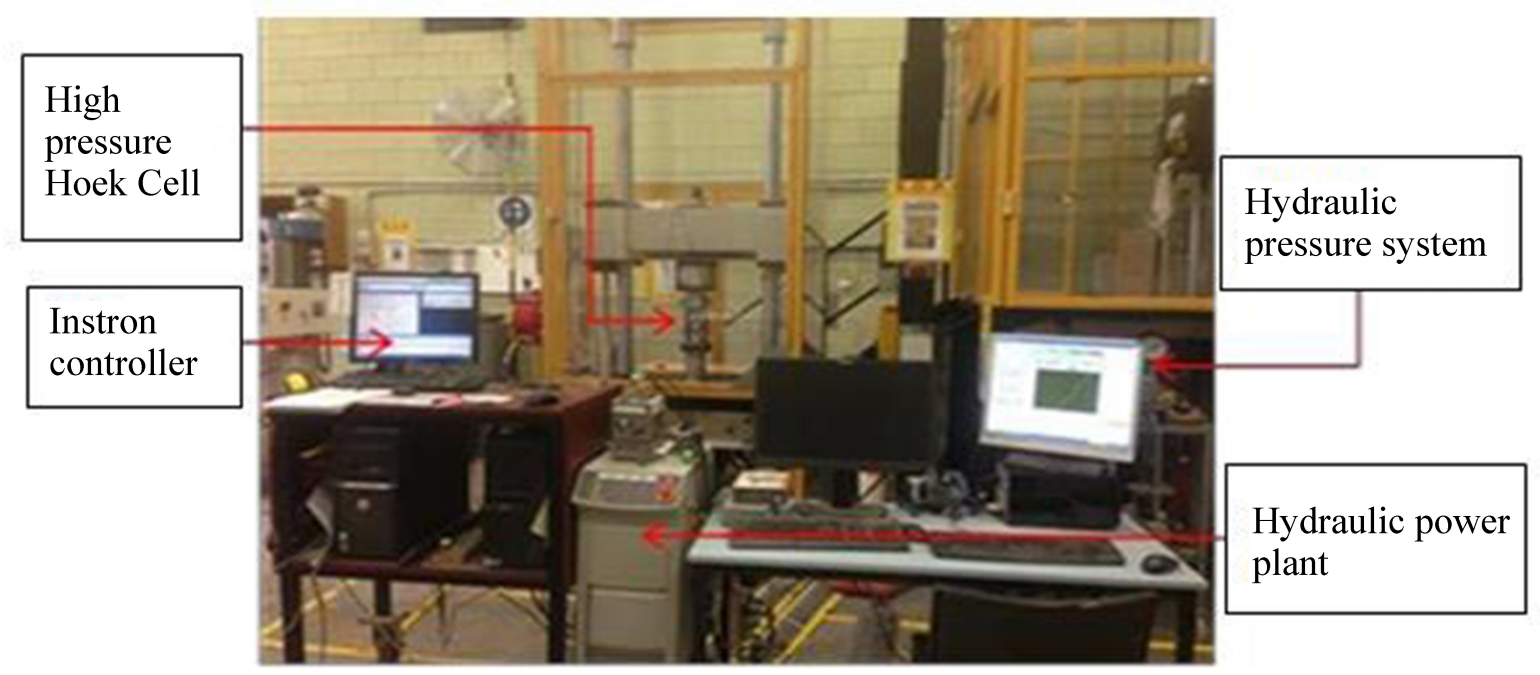

Figure 2. Uniaxial compression test experimental set-up 


\subsubsection{Monotonic Compressive Loading}

The INSTRON 1342 machine can apply different confining pressures, which can be changed between 0 and $150 \mathrm{MPa}$. A monotonic compressive load was applied to every sample. As the specimen must be intact and unaltered when a load is commencing, the monotonic load must be eliminated before irreversible damage is incurred. Every rock sample was subject to monotonically increasing pressure with the deviator stress at a $0.01 \mathrm{~mm} / \mathrm{sec}$ constant load rate until the breaking point was attained.

During the experimental testing, the applied loading has attempted to fail the rock, and the loading rate was set to $0.1 \mathrm{~mm} / \mathrm{min}$, causing the specimen to avoid discrepancies and influence the specimen to experience a rapid increase in load. Therefore, the closed-loop servo-controlled testing machine with a loading capacity of $250 \mathrm{kN}$ has a loading rate capability in the range of $0.001-10 \mathrm{~mm} / \mathrm{s}$ was set constant throughout the testing.

The rock strength at failure value for each sample was then tracked. As part of this investigation, three types of confining pressures were applied to rock specimens as follows: $0 \mathrm{MPa}, 4 \mathrm{MPa}$, and 8MPa. Hoek and Brown [9] mentioned that the maximum compressive strength is up to $50 \%$ of the total pressure that can be applied. Figure 3 demonstrates the behaviour of stress and strain of the tested rock, which exhibits the stress of the tested rock at varying confining pressures.

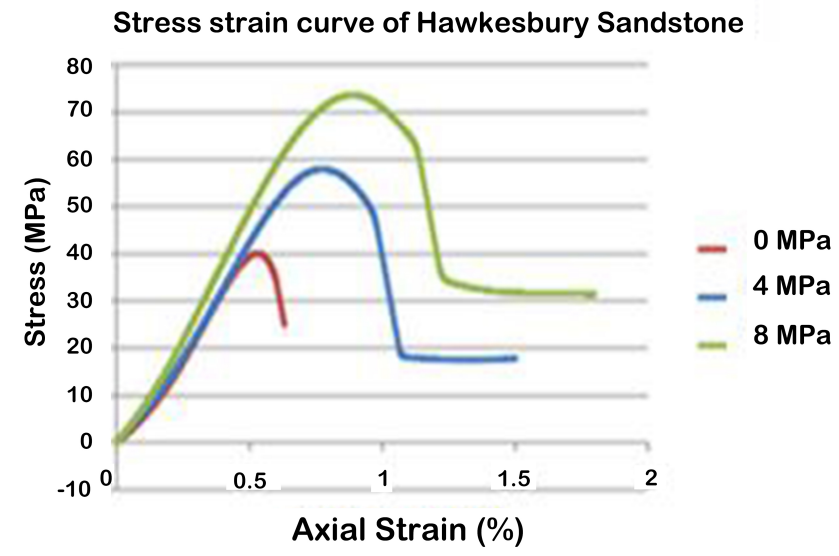

Figure 3. Hawkesbury Sandstone stress-strain curve at various confining pressures

\subsection{Results and Analysis}

A total number of 8 uniaxial tests were used in this research. There are various monotonic tests of 0,4 , and 8 $\mathrm{MPa}$ confining pressure conducted. Shearing occurs during the shearing stage of the triaxial testing process, during which the specimens are compressed axially and then expanded laterally. This is referred to as an anisotropic stress state because the applied axial and lateral loads are different. By applying deviator stress and cell pressure, the lateral pressure is generated; meanwhile, a combination of cell pressure and deviator stress is referred to as vertical pressure. Tests at confining pressures of $0 \mathrm{MPa}, 4 \mathrm{MPa}$, and 8MPA resulted in deviator stresses at the failure of $40 \mathrm{MPa}, 58 \mathrm{MPa}$, and 73 $\mathrm{MPa}$, respectively, for the three different confining pressures. These values are important in determining the normalised stress curve as in Figure 4.

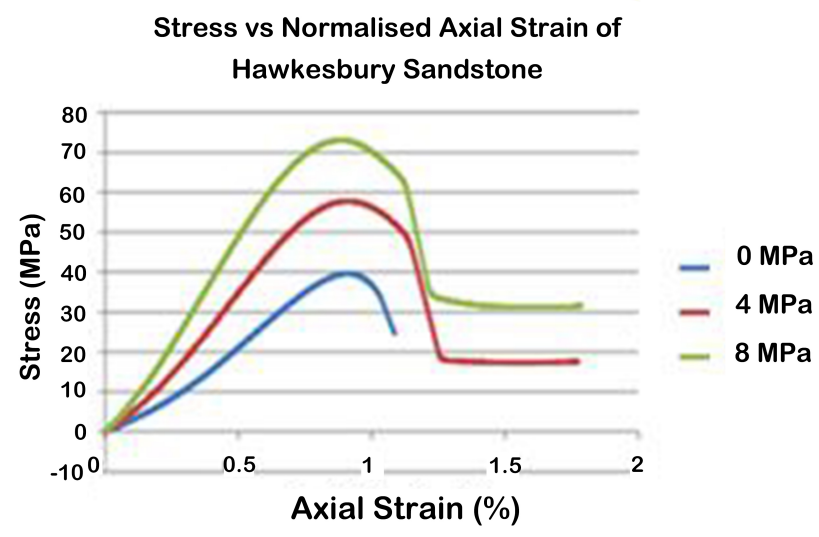

Figure 4. Curve of normalized stress-strain for various confining pressures

For the intent of gaining a better understanding of mobilised shear strength envelopes when deviator stress is applied, a normalised stress-strain curve is required. By multiplying axial strains by a standard factor with equation 1 , the standardised stress curves are produced. The conversion factor of confining pressures is $0 \mathrm{MPa}$ and $4 \mathrm{MPa} 0.49$ and 0.72 , respectively. For $8 \mathrm{MPa}$ confining pressure, the normalise conversion factor is 0.85 . Table 2 shows the complete results of the stress-strain curve.

Normalised convertion factor $=$ Maximum axial strain (\%) at failure

Axial strain (\%) at failure under considerration

Table 2. Mobilized stress strength envelope for different confining pressures

\begin{tabular}{|c|c|c|c|}
\hline Cell pressure (MPa) & $\mathbf{0}$ & $\mathbf{4}$ & $\mathbf{8}$ \\
\hline Peak Axial Strain & 0.49 & 0.72 & 0.85 \\
\hline Normalized Conversion Factor & $0.85 / 0.49$ & $0.85 / 0.72$ & $0.85 / 0.85$ \\
\hline Oo at $\mathbf{0 . 2 \%}$ axial strain (MPa) & 6.27 & 11.23 & 16.46 \\
\hline Oo at 0.4\% axial strain (MPa) & 15.61 & 26.68 & 38.11 \\
\hline Oo at 0.6\% axial strain (MPa) & 27.03 & 43.43 & 58.78 \\
\hline Oo at $\mathbf{0 . 8 \%}$ axial strain (MPa) & 37.27 & 55.75 & 71.85 \\
\hline Oo at $\mathbf{0 . 8 5 \%}$ axial strain (MPa) & 39.79 & 57.88 & 79.11 \\
\hline
\end{tabular}

The prediction of the deviator stress can be seen through the entire Mohr circle drawing in Figure 5, and the complete prediction values are shown in Table 2 . These mobilised shear strength envelopes are regarded as an inherent attribute of the tested rock, which is used to estimate deviator stress in the presence of any confining pressure. Mohr-Circle is used to define the anisotropic stress imparted to the specimen. Generally, when the 
width of the Mohr-Circle increases, the deviator stress increases. This is an equilibrium state, and the rock mass has generated a higher mobilised shear strength as a result. Different types of rock will exhibit a range of mobilised shear strength envelopes and shear strength envelopes at failure. As a result, it demonstrated the unique property of the rock.

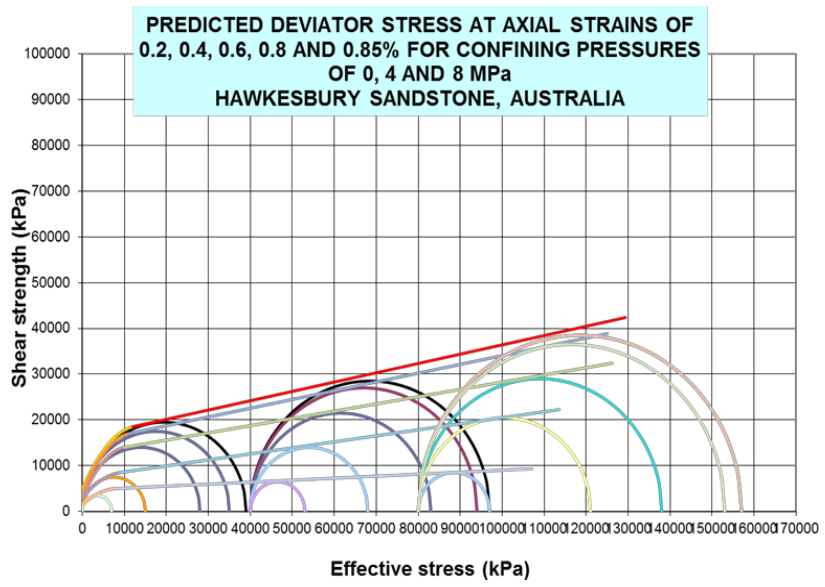

Figure 5. Hawkesbury Sandstone axial stress envelopes with mobilised shear strength

To compare stress-strain curve predictions to experimental results, the normalised strain must be multiplied by the inverse factor calculated using Equation 2 . Table 3 presents the complete prediction values. Figure 6 shows the projected stress-strain curve superimposed on the actual lab stress-strain curve of Hawkesbury Sandstone. The estimated stress-strain magnitudes for confining pressures of 0,4 , and $8 \mathrm{MPa}$ are shown in Table 3 and plotted as stress-strain curves. In comparison to the charts obtained from the laboratory tests, a very closely predicted stress response had been achieved.

Normalised inverse factor $=$ Axial strain (\%) at failure under considerration

Maximum axial strain (\%) at failure

Table 3. Mobilized stress strength envelope for different confining pressures

\begin{tabular}{|c|c|c|c|c|c|c|c|}
\hline \multicolumn{3}{|c|}{ 0 MPa } & \multicolumn{3}{c|}{ 4 MPa } & \multicolumn{2}{c|}{ 8 MPa } \\
\hline $\begin{array}{c}\text { Axial } \\
\text { Strain } \\
(\%)\end{array}$ & $\begin{array}{c}\text { Axial } \\
\text { Strain } \\
(\mathrm{x} \\
\text { inverse } \\
\text { factor })\end{array}$ & $\begin{array}{c}\text { Deviator } \\
\text { stress } \\
(\mathrm{MPa})\end{array}$ & $\begin{array}{c}\text { Axial } \\
\text { Strain } \\
(\%)\end{array}$ & $\begin{array}{c}\text { Axial } \\
\text { Strain } \\
(\mathrm{x} \\
\text { inverse } \\
\text { factor })\end{array}$ & $\begin{array}{c}\text { Deviator } \\
\text { stress } \\
(\mathrm{MPa})\end{array}$ & $\begin{array}{c}\text { Axial } \\
\text { Strain } \\
(\%)\end{array}$ & $\begin{array}{c}\text { Deviator } \\
\text { stress } \\
(\mathrm{MPa})\end{array}$ \\
\hline 0 & 0 & 0 & 0 & 0 & 0 & 0 & 0 \\
\hline 0.2 & 0.12 & 7 & 0.2 & 0.17 & 13 & 0.2 & 17 \\
\hline 0.4 & 0.23 & 15 & 0.4 & 0.34 & 28 & 0.4 & 41 \\
\hline 0.6 & 0.35 & 28 & 0.6 & 0.51 & 43 & 0.6 & 58 \\
\hline 0.8 & 0.46 & 35 & 0.8 & 0.68 & 54 & 0.8 & 73 \\
\hline 0.85 & 0.49 & 39 & 0.85 & 0.72 & 57 & 0.85 & 77 \\
\hline
\end{tabular}

The advantages that drive deformations and resisting variables are incorporated in the deformation framework. The framework is, moreover, derived from the actual behaviour of stress. Table 4 detailed the projection of Hawkesbury Sandstone stress-strain curves for the respective axial strain $(0.2,0.4,0.6,0.8$, and 0.85 per cent). This process is repeated for all mobilised shear resistance envelopes and the connection between the deviating stress and the corresponding axial stress that may comprise the prediction of straining relationships for pressure-confining differences of Hawkesbury Sandstone as shown in Figure 6.

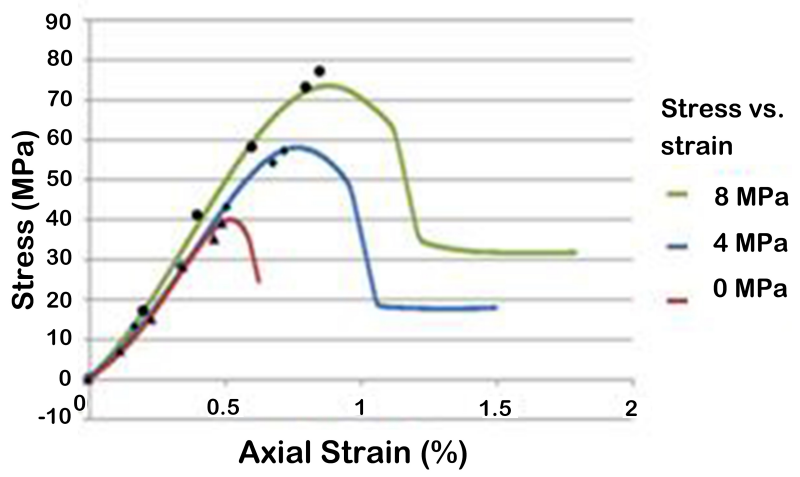

Figure 6. Predicted stress-strain curve superimposed on the Hawkesbury Sandstone's actual laboratory stress-strain curve

Table 4. Mobilized stress strength envelope for different confining pressures

\begin{tabular}{|c|c|c|c|}
\hline Axial Strain (\%) & Oo at 0MPa & Oo at 4MPa & Oo at 8MPa \\
\hline & & & \\
\hline 0.2 & 7 & 13 & 17 \\
\hline 0.4 & 15 & 28 & 41 \\
\hline 0.6 & 28 & 43 & 58 \\
\hline 0.8 & 35 & 54 & 73 \\
\hline 0.85 & 39 & 59 & 77.5 \\
\hline
\end{tabular}

\subsubsection{Monitoring of Specimen, Vertical and Lateral} Displacement during Shearing

The vertical compression of the specimen and the lateral dilation during shearing are monitored using LVDT's assembled, as shown in Figure 7. The latter substantiated that there is consideration of anisotropic condition. The graphically relationships between the stress and strain of each confined rock specimen in terms of the axial strain, lateral strain, LVDT, and volumetric strain would be exclusively highlighted in the research. The volumetric strain referred to the summations of the average of axial strain, and the doubled of average lateral strains recorded by the strain gauge. The volumetric strain of each specimen can be calculated using Equation 3, which is shown as follows:

$$
\varepsilon_{\text {volumetric }}=\varepsilon_{\text {axial }}+2 \text { Elateral }
$$

Where,

Evolumetric $=$ Volumetric strain

Eaxial $=$ Average axial strain recorded from two axial 
strain gauges

Elateral $=$ Average lateral strain recorded from two lateral strain gauges

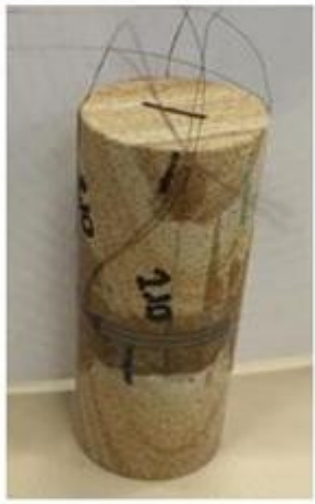

(a)

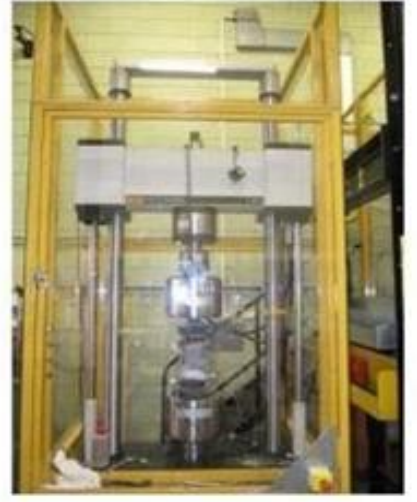

(b)
Figure 7. (a) Strain Gauge (b) Measurement of LVDT

In addition to that, the stress-strain graphs in this section show plots of the axial strain measured by the LVDT, the axial and lateral strain recorded by the gauges as well as the volumetric strain. Strain gauges are an accurate means of measuring the strain that each rock specimen is under during testing compared to the strain measured from the LVDT. Unfortunately, sometimes gauges are not always reliable as failure occurs commonly even after protection methods have been applied.

Figure 8 shows the relationship of volumetric strain with the axial and lateral strain of the specimen for this research. Figure 8(a) illustrates similar results for the uniaxial compressive loading test, while both Figure 8(b) and Figure 8(c) are demonstrating similar results for 4 $\mathrm{MPa}$ and $8 \mathrm{MPa}$ confinements, respectively. In the beginning, the specimen exhibited volumetric compaction followed by volumetric dilation. The volumetric strain decrease with axial and lateral strain after the peak strength is reached. This could be explained by the fact that volumetric compaction induces the hardening of the specimen, thus incurring the crack damage.

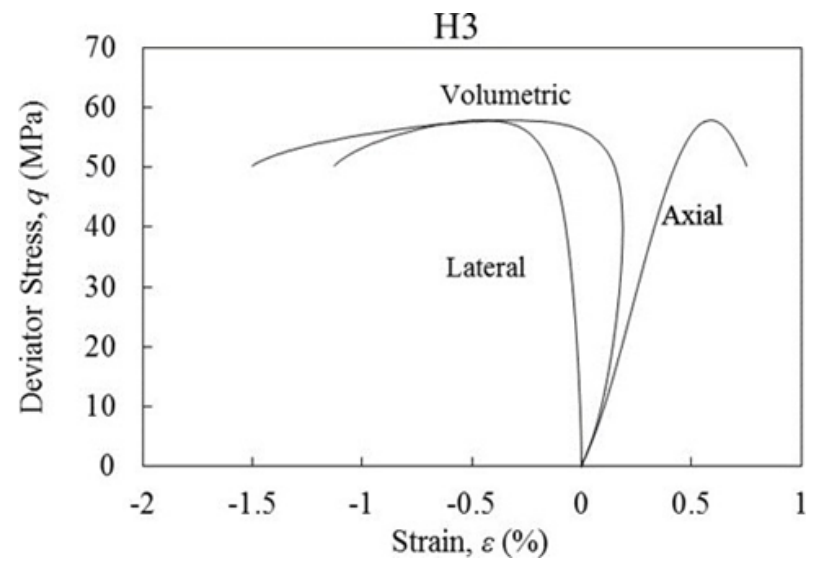

a) $0 \mathrm{MPa}$

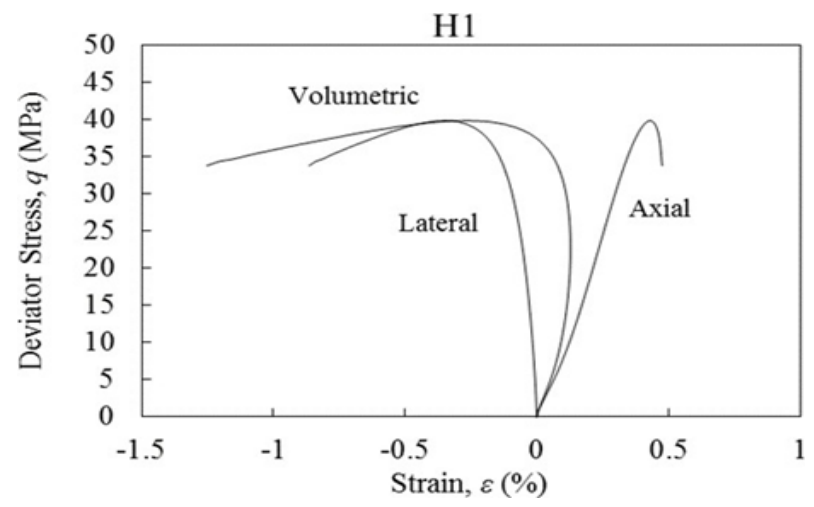

b) $4 \mathrm{MPa}$

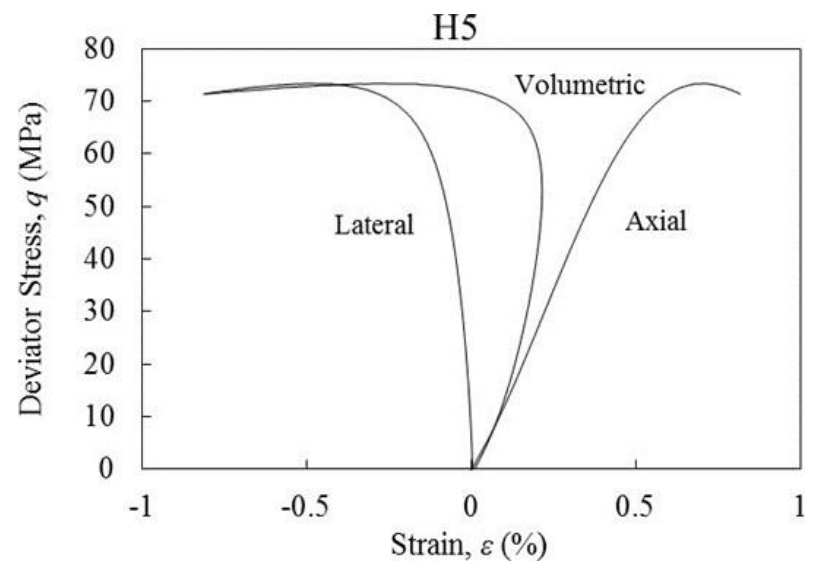

c) $8 \mathrm{MPa}$

Figure 8. Volumetric strain relation with axial and lateral strain for a) $0 \mathrm{MPa}$, b) $4 \mathrm{MPa}$ and c) $8 \mathrm{MPa}$

Md Noor and Jobli [10] stated a new theoretical approach for calculating anisotropic rock deformation models had been developed, and the model incorporates the stress-strain curves for rock in isotropic compression to derive the mobilisation of shear strength. The relationship between the position of the mobilised shear strength envelopes and the axial strain is regarded as an inherent property of the rock mass, and it is used to predict the rock stress-strain response under anisotropic stress conditions. In order to identify the location of the mobilised shear strength envelopes, a pilot run is performed, during which the mobilised minimum friction angle is recorded. When the rock is subject to anisotropic compression, this inherent mobilised shear strength essentially increases, as demonstrated by the envelope rotating upward toward the shear strength envelope at failure. This incorporates the mobilised shear force in the characterization of the rock deformation in terms of the applied stress.

Previous studies have confirmed laboratory testing of anisotropic rocks has been carried out in recent years by considering:

1) rocks which would be expected to behave as isotropic media and exhibit anisotropic properties (Class A) 
2) rocks that are clearly anisotropic in nature and show directions of symmetry for their strength and deformation characteristics (Class B).

The anisotropic of rock can be an effect produced by microfractures and narrow cavities between adjacent particle boundaries in the rock. The stress-strain curve for the same rocks at low to moderate stress levels is nonlinear, which shows a concave upward curvature as shown in Figure 9. Thus, the nonlinear and anisotropic behaviour have the same origin [11].

\section{Sample V24 (0 MPa)}

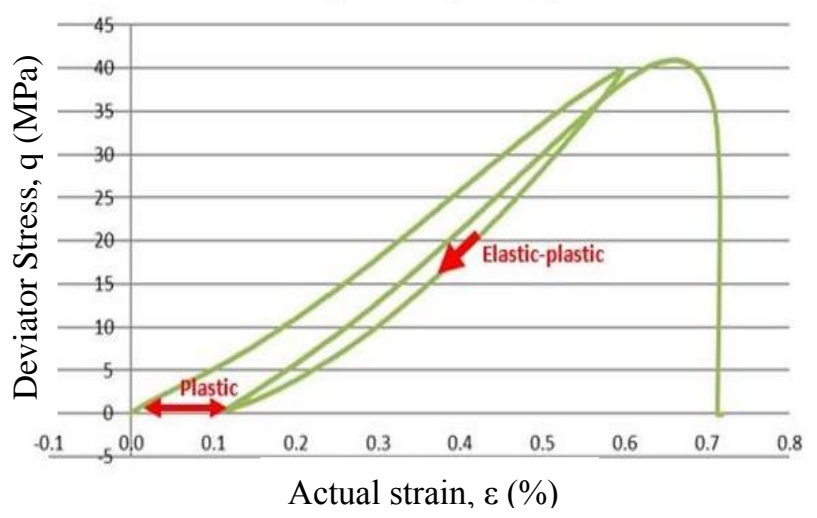

a) Stress-strain curve based on actual strain

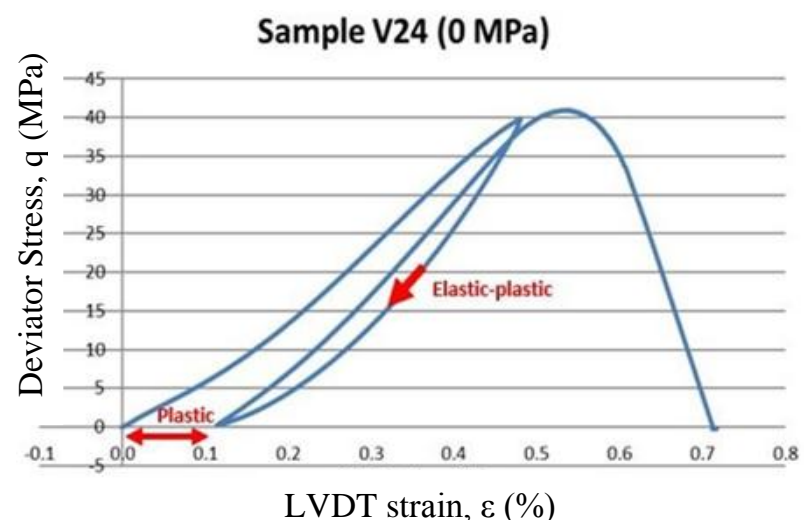

b) Stress-strain curve based on LVDT strain

Figure 9. Anisotropic volume change of rock based on a) Actual strain b) LVDT strain

Ge et al. [12] examined the three stages of fatigue behaviour: volumetric compaction, volumetric dilation with strain hardening behaviour, and volumetric dilation with strain-softening behaviour. It was found that the threshold for fatigue failure occurred at the transition point between volumetric compaction and volumetric dilation.

\section{Conclusions}

The mobilised shear strength was determined in this study using a stress-strain curve and an anisotropic deformation model in which the rock is compressed in an anisotropic manner. The magnitude of the mobilised shear strength envelope in relation to the corresponding axial strain revealed the inherent property of the unique rock mass. The properties are utilised as guidelines for predicting rock stress-strength behaviour under anisotropic stress conditions. The research revealed that, based on mobilised minimum friction angle, the location of the mobilised shear strength envelope is considered. When the rock is compacted, however, the inherent mobilised shear strength of the rock increases due to the compaction process. As proven in this study, the envelope rotates upwards at the shear stress envelopes, demonstrating the phenomenon. Cementation $\left(c^{\prime}\right)$ on the rock appears to increase, as can be seen in Table 5 .

Table 5. Inherent properties of Hawkesbury Sandstone from mobilised shear strength envelopes Prediction of stress-strain behaviour of Hawkesbury Sandstone

\begin{tabular}{|c|c|c|}
\hline Axial (\%) & Cement (kPa) & Friction angle (deg) \\
\hline 0.2 & 1500 & 2.5 \\
\hline 0.4 & 3000 & 7.5 \\
\hline 0.6 & 3000 & 9.00 \\
\hline 0.8 & 4000 & 10.85 \\
\hline 0.85 & 5000 & 11.5 \\
\hline
\end{tabular}

This research allows explaining the resultant deformation occurrence whereby at the point above the stress level where crack initiation occurs, the deformation in successive loads is cumulative. It is proposed that when the strain energy stored in the specimen exceeds a critical energy level, the failure occurs. Critical energy defined that it is equivalent to static loading (non-cyclic). Equation 1 given by Ge et. al. (2003) is an expression for decomposition where total strain $=$ reversible strain + irreversible strain $=$ reversible strain + plastic deformation + fatigue deformation. The monotonic loading causes the strain component by plastic deformation.

\section{Acknowledgments}

The authors would like to express their gratitude to the School of Civil, Environmental and Mining Engineering, University of Adelaide Australia and School of Civil Engineering, College of Engineering, Universiti Teknologi MARA Malaysia for the laboratory expertise and contribution to this research.

\section{REFERENCES}

[1] W. Liang, C. Zhang, H. Gao, X. Yang, S. Xu and Y. Zhao Experiments on Mechanical Properties of Salt Rocks under Cyclic Loading, Journal of Rock Mechanics and Geotechnical Engineering, Vol.4, Issue 1, 54-6, 2012. 
[2] A.A. Al-Harthi. Effect of Planar Structures on the Anisotropy of Ranyeh Sandstone, Saudi Arabia. Engineering Geology, Vol.50, Issues 1-2, 49-57, 1998.

[3] A. Taheri, N. Hamzah and Q. Dai. Degradation and Improvement of Mechanical Properties of Rock under Triaxial Compressive Cyclic Loading. Japanese Geotechnical Society Special Publication, International Mini Symposium CHUBU (IMS-CHUBU), Vol.5, Issue 2, 71-78, 2017.

[4] E.T.Mohamad, I. Kamoo, K.A. Kassim, and N. Gofar. Influence of Moisture Content on The Strength of Weathered Sandstone. Malaysian Journal of Civil Engineering, Vol.20, Issue 1, 137-144, 2008.

[5] Z. Mohamed, H. Awang, and K. Mohamed. Empirical Strength Models, Elastic Modulus and Stiffness of Weathered Sandstone and Shale as A Composite Rock, EJGE, 2007.

[6] J.P. Yang, W.Z. Chen, D.S. Yang and J.Q. Yuan. Numerical Determination of Strength and Deformability of Fractured Rock Mass by FEM Modelling. Computers and Geotechnics, Vol.64, 20-31, 2015.

[7] Y. Xu and M. Cai. Numerical Study on the Influence of
Cross-Sectional Shape on Strength and Deformation Behaviours of Rocks Under Uniaxial Compression. Computers and Geotechnics, Vol.84, 129-137, 2016.

[8] E.T. Brown (Editor). International Society for Rock Mechanics (ISRM): Rock Characterization, Testing and Monitoring, ISRM Suggested Methods. Pergamon Press, Oxford, 1981.

[9] E. Hoek and E.T. Brown. Empirical Strength Criterion for Rock Masses. Journal of the Geotechnical Engineering Division, Vol. 106, Issue 9, 1980.

[10] M.J. Md Noor and A.F. Jobli. A State-of-the-Art Anisotropic Rock Deformation Model Incorporating the Development of Mobilized Shear Strength. IOP Conference Series: Earth and Environmental Science, Vol.140, 012074, 2018.

[11] G. Barla. Rock Anisotropy - Theory and Laboratory Testing. In: Müller L. (eds) Rock Mechanics. International Centre for Mechanical Sciences (Courses and Lectures), Springer Vienna, Vol.165, 131-169, 1974.

[12] X. Ge, Y. Jiang, Y. Lu and J. Ren. Testing Study on Fatigue Deformation Law of Rock Under Cyclic Loading. Chinese Journal of Rock Mechanics and Engineering, Vol.22, Issue $10,1581-1585,2003$. 